\title{
Determining Major Genotypes of Hepatitis C Virus Among Transplant Recipients by Real-Time Polymerase Chain Reaction Assay
}

\author{
Roya Feyznezhad ${ }^{1}$; Mohammad Amin Behzadi ${ }^{2,3}$; Ramin Yaghobi ${ }^{4}$; Mazyar Ziyaeyan ${ }^{2, *}$ \\ ${ }^{1}$ Department of Microbiology, Sciences and Research Branch, Islamic Azad University, Shiraz, IR Iran \\ 2 Alborzi Clinical Microbiology Research Center, Namazi Hospital, Shiraz University of Medical Sciences, Shiraz, IR Iran \\ ${ }^{3}$ Student Research Committee, Shiraz University of Medical Sciences, Shiraz, IR Iran \\ ${ }^{4}$ Student Research Committee, Shiraz University of Medical Sciences, Shiraz, IR Iran
Shiraz Transplant Research Center, Shiraz University of Medical Sciences, Shiraz, IR Iran \\ ${ }^{*}$ Corresponding author: Mazyar Ziyaeyan, Alborzi Clinical Microbiology Research Center, Namazi Hospital, Shiraz University of Medical Sciences, Shiraz, IR Iran. Tel: +98-7193711351, \\ Fax: +98-7116474303, E-mail:ziyaeyanm@sums.ac.ir
}

Received: December 9, 2013; Revised: June 8, 2014; Accepted: June 24, 2014

\begin{abstract}
Background:Hepatitis C virus (HCV) infection still exists as a health concern among the transplant patients. Because of the severity of the disease, different responses to treatment, and side effects resulting from long therapeutic period, determination of genotypes and viral loads can help choose the best treatment protocols.

Objectives: This study aimed to determine the HCV genotypes and its distribution patterns among liver, kidney, and bone marrow recipient candidates across Iran, referred to Namazi Hospital, southern Iran.

Patients and Methods: A total of 101 individuals, including 44 (43.6\%) liver, 55(54.5\%) kidney, and 2 (2\%) bone marrow recipient candidates, with ages ranging between 5 and 74 years (Mean \pm SD: $46.53 \pm 13.73$ y) participated in this study. From those, whole blood sample were collected and anti-HCV antibodies, RNA detection, and genotyping were performed on plasma using commercial chromatographic immunoassay, TaqMan one-step real-time polymerase chain reaction (RT-PCR), and genotyping RT-PCR kits, respectively. The frequencies of anti-HCV antibodies, RNA, various genotypes, and the viral load were compared with respect to gender, age, and transplant recipient groups.

Results: Of 101 individuals, 47 (46.5\%) were positive for anti-HCV antibodies and 34 (33.7\%) for RNA with a significant difference $(\mathrm{P}<0.05)$. RNA copy number ranged from $4.6 \times 103$ to $3.11 \times 107$ copies $/ \mathrm{mL}$, median: $2.92 \times 106$ copies $/ \mathrm{mL}$, with no statistical differences in all groups. Analyses revealed no significant differences between the frequencies of anti-HCV antibodies or RNA in different groups. The frequencies of the genotypes 1(50\%) and 3 (35.3\%) were higher than those of the genotypes 2 (2.9\%), 4 (2.9\%), and undetermined one (8.8\%). Genotype 1 was significantly more prevalent in liver transplant recipients, those older than 40 years, and male cases $(\mathrm{P}<0.05)$.

Conclusions: Considering the high frequency of genotypes 1 and 3 among the studied groups, it is suggested that before and after transplantation programs be improved to manage and treat the disease efficiently, based on the standard protocols for such genotypes in the region. Accordingly, the occurrence of post-transplant complications due to immunosuppression among all the recipients as well as reinfection in HCV infected liver transplant patients can be diminished.
\end{abstract}

Keywords:Hepatitis C Virus; Transplant Recipient, Iran

\section{Background}

Unfortunately, hepatitis C virus (HCV) infection still exists as a main health concern, which causes several complications among the infected transplant patients. The virus belongs to the Hepacivirus genus in the family Flaviviridae with 7 known major genotypes $(1,2)$. Numerous studies report the controversial effects of the infection before and after transplantation. Recurrence of the disease is asserted in the liver transplant patients who were viremic before the operation (3), which may develop to cirrhosis in at least $25 \%$ of them within 5 years of transplantation (4). Previous studies indicated that $\mathrm{HCV}$ infection can cause liver failure among chronic renal failure (CRF) patients within a long time after kidney transplantation (5, 6). Besides liver damage, various types of renal diseases such as glomerular disease and its outcomes may occur post HCV infection
$(7,8)$. In addition, renal transplantation survival is also reduced in the individuals with chronic HCV infection (911). Thus, an appropriate antiviral therapy before and after transplantation, and development of HCV treatment strategies are important, especially among this group. Because of the severity of the disease, different responses to treatment and side effects resulting from long therapeutic period (12-14), determination of various genotypes and viral loads among the infected patients can help the clinicians to choose the best HCV therapeutic protocols. Moreover, the prognosis of the transplantations can be facilitated by HCV genotype detection. Although some studies have reported the frequency of HCV genotypes among Iranian populations, a few studies have addressed it among transplant patients in Iran.

Copyright (C) 2015, Ahvaz Jundishapur University of Medical Sciences. This is an open-access article distributed under the terms of the Creative Commons Attribution-NonCommercial 4.0 International License (http://creativecommons.org/licenses/by-nc/4.0/) which permits copy and redistribute the material just in noncommercial usages, provided the original work is properly cited. 
Feyznezhad Ret al.

\section{Objectives}

This study aimed to determine the HCV genotypes and its distribution pattern among recipient candidates across Iran, referred to Namazi Hospital, Shiraz, southern Iran.

\section{Patients and Methods}

\subsection{Study Population}

The population involved transplant recipient candidates all across Iran, referred to Professor Alborzi Clinical Microbiology Research Center, Namazi Hospital, Fars Province, between September 2011 and January 2013, for the diagnosis of HCV infection. All individuals had an indication for the infection diagnosed by the clinicians or previously infected with the virus and were under HCV treatment. The patients were divided into three recipient groups, based on the type of transplantation, i.e. liver, kidney, and bone marrow. They were also categorized into two age groups: group I ( $\leq 40$ years) and group II ( $>40$ years).

\subsection{Sampling, Anti-HCV Antibody Detection, and RNA Extraction}

The plasma from $5 \mathrm{~mL}$ blood samples of each individual was separated at $5000 \mathrm{rpm}$ for 5 minutes, aliquoted, labeled, and kept at $-70^{\circ} \mathrm{C}$ until further steps. Plasma samples were first examined with a commercial rapid anti-HCV antibodies test kit (Cat No: A02-06-213; Artron Laboratory Inc., Canada). The kit was a chromatographic immunoassay for the qualitative detection of anti-HCV antibodies in the plasma or serum. As indicated by the manufacturer, its sensitivity and accuracy were $2 \mathrm{NCU} / \mathrm{mL}$ and $99 \%$, respectively. RNA was extracted from a $200 \mu \mathrm{L}$ volume of each plasma sample, using a commercially available viral RNA isolation kit (Invitek, Berlin, Germany), as per manufacturer's instructions. To monitor the quality of nucleic acid extraction process, the omission of reverse transcription and PCR inhibitors, and the cDNA synthesis step, a standardized amount of internal control RNA, supplied with the real-time PCR kit, was added to the lysis buffer. For every 20 clinical samples, both negative and positive controls were included in the extraction process.

\subsection{Real-Time Reverse Transcription Polymerase Chain Reaction for Hepatitis C Virus Detection}

HCV RNAs in all the samples were detected and quantified using the commercially available real-time polymerase chain reaction RT-PCR Advanced Kit (Primerdesign Ltd., Millbrook Technology Campus, Southampton, UK) with the sensitivity of 1000 copies of viral RNA per $1 \mathrm{~mL}$ plasma sample, based on our dilution factor. All reactions were performed in a 7500 Real-time PCR System instrument (Applied Biosystems, USA) using TaqMan onestep RT-PCR master mix reagents (Invitrogen, Carlsbad,
Canada). According to the manufacturer's protocol, the temperature profile of PCR machine was adjusted at $50^{\circ} \mathrm{C}$ for 20 minutes for reverse transcription and $95^{\circ} \mathrm{C}$ for 10 minutes for DNA polymerase activation, followed by 50 cycles, each of 10 seconds denaturation at $94^{\circ} \mathrm{C}$ and $60^{\circ} \mathrm{C}$ for 60 seconds for annealing and extension, respectively.

\subsection{Real-time Reverse Transcription Polymerase Chain Reaction for Hepatitis C Virus Genotyping}

To detect different HCV genotypes $(1,2,3$, and 4$)$ in the determined RNA positive plasma samples in the previous step, commercial RT-PCR kit (Genome Diagnostics Pvt. Ltd., Hague, Netherland) was applied. The modified amplification process was as follows: $50^{\circ} \mathrm{C}$ for 25 minutes and $95^{\circ} \mathrm{C}$ for 10 minutes, followed by 50 cycles of $94^{\circ} \mathrm{C}$ for 10 seconds, $55^{\circ} \mathrm{C}$ for 32 seconds, and $72^{\circ} \mathrm{C}$ for 25 seconds.

\subsection{Statistical Analysis}

The comparison of HCV RNA detection and antibody detection results were done in combination and separately in different age, gender, and recipient groups, using chisquare test. Moreover, the normality of the distribution pattern of the RNA values (copies/mL) in the studied population was initially explored with 1-sample KolmogorovSmirnov test. Based on the results, the distribution is not normal if the difference is significant $(\mathrm{P}<0.05)$. Therefore, the Kruskal-Wallis $\mathrm{H}$ test was used to compare the viral load (Mean $\pm S D$ ) in different genotypes and transplant recipient groups, and the Mann-Whitney test was applied for statistical comparisons of HCV RNA level in different age and gender groups. In addition, the association between the prevalence of different HCV genotypes in various gender, age, and transplant recipient groups was analyzed using chi-square test. Statistical analysis was done by SPSS for Windows (version 16, SPSS Inc., Chicago, IL, USA) and the data were considered statistically significant at a two sided P value of less than 0.05 .

\section{Results}

Out of the 101 referred individuals, 44 (43.6\%), 55 (54.5\%), and $2(2 \%)$ patients were the recipient candidates of liver, kidney and bone marrow, respectively. Patients' age ranged from 5 to 74 years (mean \pm SD: $46.53 \pm 13.73 \mathrm{y}$ ). They consisted of 59 (58.4\%) men and 42 (41.6\%) women. From those, 47 (46.5\%) and 34 (33.7\%) were positive for anti-HCV antibodies and RNA, respectively, with a significant difference in corresponding prevalence rates $(P<0.05)$. The copy number of HCV RNA, measured by the real-time PCR assay, ranged from $4.6 \times 103$ to $3.11 \times 107$ copies/mL and median as $2.92 \times 106$ copies $/ \mathrm{mL}$. Medical records revealed that the entire positive anti-HCV antibodies and/or RNA patients were already under treatment. However, statistical analysis revealed no significant differences between the frequencies of anti-HCV antibodies or RNA in different age, gender, and recipient groups $(\mathrm{P}<0.05$, Figure 1$)$. 


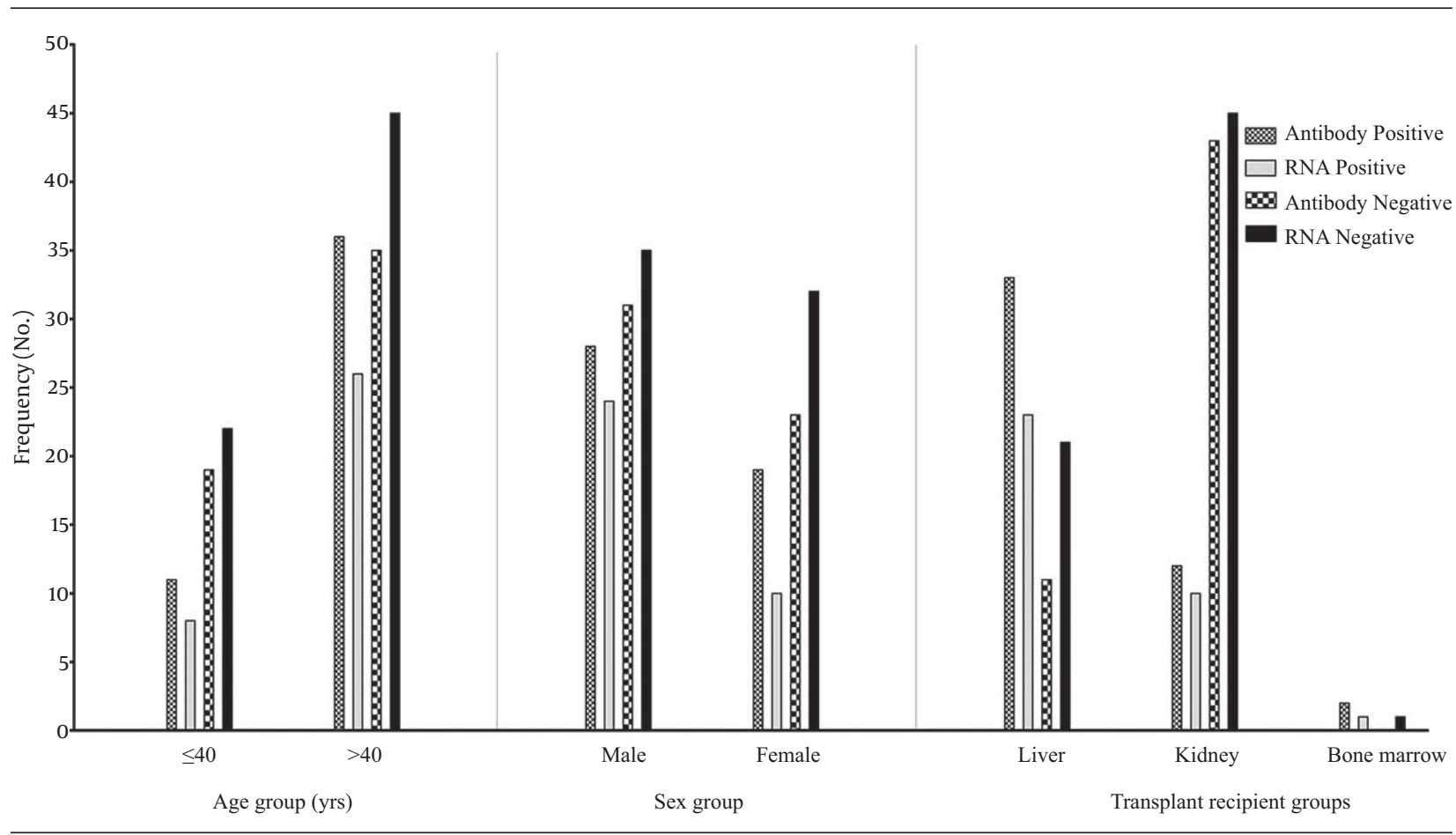

Figure 1. The Frequencies of Anti-HCV Antibodies and HCV RNA in Different Age, Gender, and Transplant Recipient Groups Among Recipient Candidates ( $\mathrm{n}=101)$, From September 2011 to January 2013, Shiraz, Southern Iran

Table 1. The Frequency of HCV Genotypes in Different Recipient, Age, and gender Group among Transplant Recipient Candidates, From September 2011 to January 2013, Shiraz Southern Iran

\begin{tabular}{|c|c|c|c|c|c|c|}
\hline \multirow[t]{2}{*}{ Groups } & \multicolumn{5}{|c|}{ HCV Genotype } & \multirow[t]{2}{*}{ P Value } \\
\hline & $\mathbf{1}$ & 2 & 3 & 4 & Undetermined & \\
\hline \multicolumn{7}{|c|}{ Recipient group } \\
\hline Liver & $14(60.9 \%)$ & $0(0.0 \%)$ & $6(26.1 \%)$ & $1(4.3 \%)$ & $2(8.7 \%)$ & 0.000 \\
\hline Kidney & $2(20.0 \%)$ & $1(10.0 \%)$ & $6(60.0 \%)$ & $0(0.0 \%)$ & $1(10.0 \%)$ & 0.079 \\
\hline Bone Marrow & $1(100.0 \%)$ & $0(0.0 \%)$ & $0(0.0 \%)$ & $0(0.0 \%)$ & $0(0.0 \%)$ & \\
\hline \multicolumn{7}{|l|}{ Age } \\
\hline$\leq 40$ & $2(25.0 \%)$ & $1(12.5 \%)$ & $4(50.0 \%)$ & $1(12.5 \%)$ & $0(0.0 \%)$ & 0.392 \\
\hline$>40$ & $15(57.7 \%)$ & $0(0.0 \%)$ & $8(30.8 \%)$ & $0(0.0 \%)$ & $3(11.5 \%)$ & 0.015 \\
\hline \multicolumn{7}{|l|}{ Gender } \\
\hline Male & $12(50.0 \%)$ & $1(4.2 \%)$ & $8(33.3 \%)$ & $1(4.2 \%)$ & $2(8.3 \%)$ & 0.000 \\
\hline Female & $5(50.0 \%)$ & $0(0.0 \%)$ & $4(40.0 \%)$ & $0(0.0 \%)$ & $1(10.0 \%)$ & 0.273 \\
\hline
\end{tabular}

Of 34 HCV RNA positive individuals, 17 (50\%), 1 (2.9\%), 12 (35.3\%), 1 (2.9\%), and 3 (8.8\%) cases had 1, 2, 3, 4, and undetermined genotypes, respectively (Figure 2 ). Table 1 presents the comparison between the frequencies of HCV genotypes in different recipient, age, and gender groups. The results showed that the frequencies of the genotypes 1 and 3 were higher than those of the genotypes 2, 4, and undetermined one. Statistical comparison of HCV RNA level in different age, gender, genotype, and transplant recipient groups revealed no significant differences $(\mathrm{P}<0.05)$. Figure 3 demonstrates the distribution patterns of HCV genotypes among different gender and transplant recipient groups in Iran. 


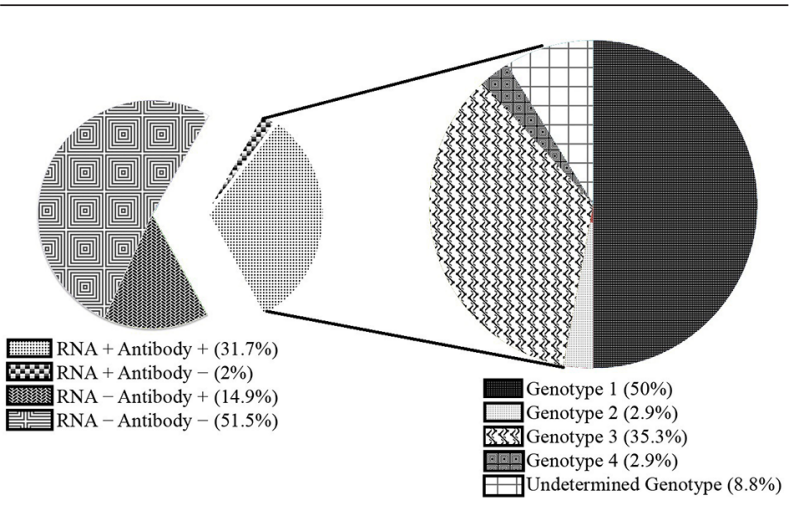

Figure 2. The Frequencies of Anti-HCV Antibodies, HCV RNA, and Different Genotypes (1, 2, 3, 4, and Undetermined) in Transplant Recipient Candidates, From September 2011 to January 2013, Shiraz, Southern Iran

\section{Discussion}

The present study was conducted on 101 liver, kidney, and bone marrow recipient candidates with indication for HCV infection, in southern Iran. Among those, HCV
RNA was detected in $33.7 \%$ of cases. HCV genotyping revealed that genotype 1 (50\%) was the most common one followed by genotype 3 (35.3\%), consistent with the results of the previous studies from Iran (15-17). A recent 9-year study on 11561 Iranian patients with chronic infection, showed that the highest frequency belonged to subtype 1a as $44.9 \%$, followed by subtype 3a as $39.6 \%$, and $1 \mathrm{~b}$ as $11.3 \%$ (18). However, in neighboring Arab countries in the Middle East except Jordan, the HCV genotype distribution pattern is completely different; in many of them, the most prevalent genotype was 4 (19). The presence of genotypes 4 or 2 among the Iranian population may be related to some factors such as communication with Arab countries or previous injection with exotic infected blood products. In the present study, the only individual in the genotype 4 and liver transplant group was a hemophilic patient with the history of receiving exotic blood products. The one in the genotype 2 and kidney transplant group living in a southern province, used to travel for work to the countries bordering the Persian Gulf. These findings may suggest that they were infected with the virus from an exotic source.

Figure 3. The Distribution Patterns of HCV Genotypes Among Different Sex and Transplant Recipient Groups, in HCV Infected Transplant Recipient Candidates, From September 2011 to January 2013, Shiraz, Southern Iran

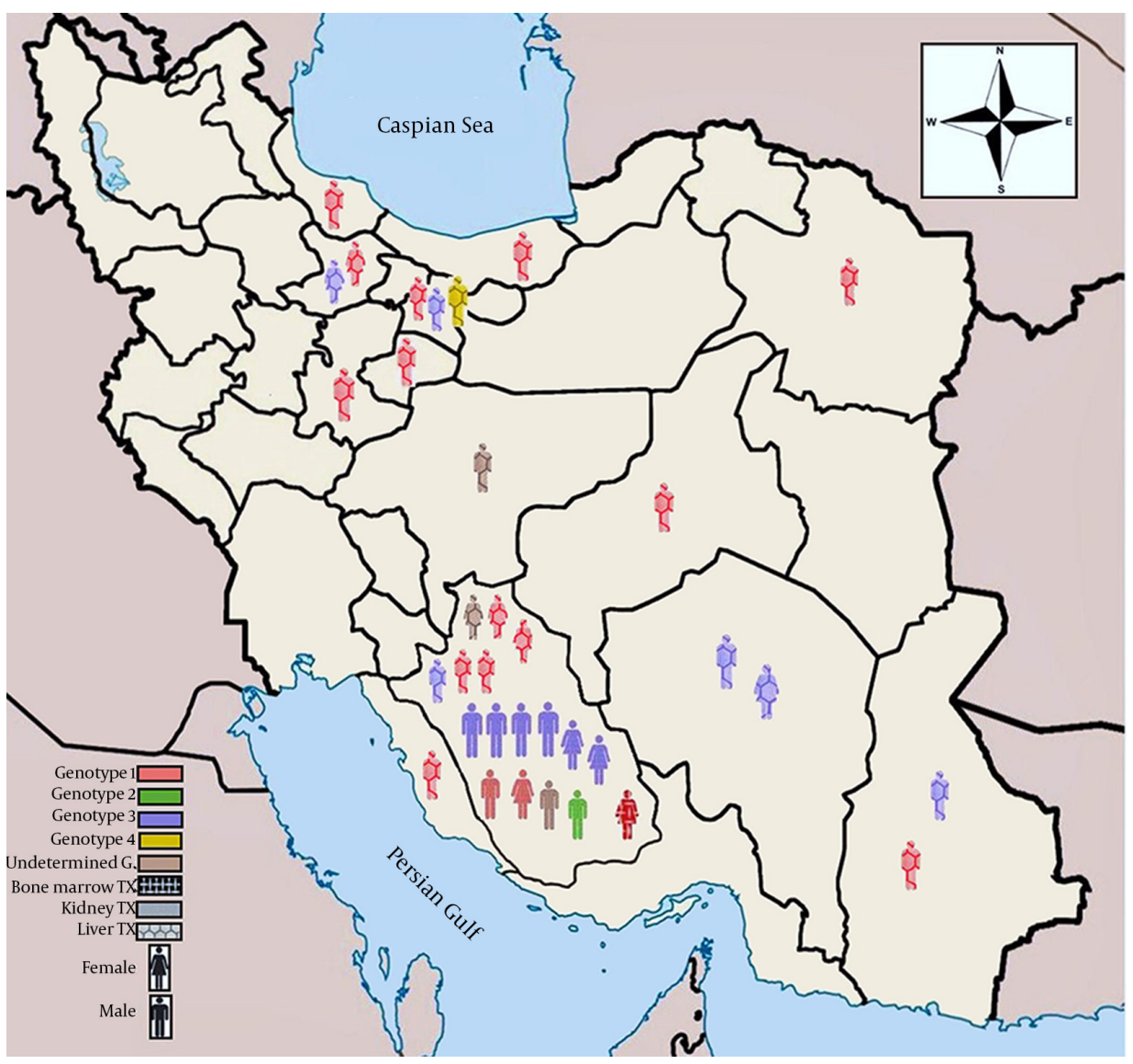

G, Genotype; TX, Transplant, $\mathrm{n}=34$ 
Of 101 patients, $46.7 \%$ were positive for anti-HCV antibodies, while the frequency of RNA positive patients (33.7\%) was significantly lower. One possibility could account for such a difference. Considering the HCV treatment in all these positive patients, it may be concluded that approximately one third was responsive to antiviral therapy (15 patients were in anti-HCV antibodies positive, RNA negative group) and the 32 remaining patients (anti-HCV antibodies positive, RNA positive group) might have had exposure to the virus recently and are under treatment or may be in HCV non-responder group with the high risk of liver damage development leading to the transplantation. Previous studies argued the presence of HCV RNA in the absence of anti-HCV antibodies status, exceptionally observed in immunocompromised subjects like HIV patients, patients on chemotherapy or dialysis, as well as, any condition that suppresses or modifies the anti-HCV antibodies response $(20,21)$.

A recent study on 514 hemodialysis patients in Iran revealed that $11.9 \%$ and $6.2 \%$ were positive for anti-HCV antibodies and RNA, respectively and the most frequent genotype was 1a, followed by $3 a$ (22). In the present study, the same condition was detected in two kidney transplant patients with regular hemodialysis history, who were infected with genotype 3 . To sum up, although the serological tests are valuable for HCV detection and screening among the population, some limitations still exist. Thus, to make an accurate HCV diagnosis and pursuing effective treatment before and after transplantation, HCV RNA detection seems to be vital. In doing the best HCV treatment and making an appropriate prognosis of the disease, both HCV viral load and genotype must be recognized and considered. The results showed that genotype 1 was significantly more frequent in liver transplant group, those older than 40 years, and male subjects $(\mathrm{P}<$ $0.05)$. As expected, viral load did not statistically vary in different age, gender, genotype, and transplant recipient groups. This may be attributed to chronicity pattern of the infection and anti-viral treatment.

The association of genotype 1 with high severity of liver disease, in comparison with genotypes 2 and 3, was documented previously based on HCV viral load (23). The high frequency of genotype 1 among liver transplant group in this study may indicate this severity; however, the viral load was not significant. Analyzed data of the genotypes between the two age groups showed that there were two patterns for the distribution of HCV genotypes; genotype 1 in older ones ( $>40$ years, higher and statistically significant) and genotype 3 in young individuals ( $\leq 40$ years, higher but not statistically significant), which was in consistent with the studies on non-transplant population in Iran and other countries (18, 24-26). Such evidence may suggest prospective HCV genotype changes among both transplant and non-transplant populations in Iran. As reported before, genotypes 1 and 3 are usually found in the individuals with the history of blood transfusion and intravenous drug abusers, respectively (27-29). In the present study, genotype 1 followed by 3 was found to be more common in males than other genotypes indicating the predominant transmission routes of such genotypes among them. Thus, controlling measures to reduce the respective risk factors are warranted.

Considering the high frequencies of genotypes 1 and 3 among the studied groups, it is suggested that existing before and after transplantation programs be improved to manage and treat the disease efficiently, based on the standard protocols for such genotypes in the region. Although several aspects of HCV recurrence have been known, a definitive strategy has not been developed to prevent the infection among liver transplant patients. Likewise, in other transplant recipients, including kidney and bone marrow transplant patients with the respective genotypes, because of complicated conditions due to immunosuppressive therapy, antiviral therapy should not only manage the HCV infection status but also reduces the side effects of treatments on the survival of transplantation. In doing so, the occurrence of post-transplant complications can be diminished among all the recipients and re-infection in HCV infected liver transplant patients.

\section{Acknowledgements}

Our thanks are due to Hassan Khajehei for copy editing of the manuscript.

\section{Funding/Support}

The study was financially supported by Professor Alborzi, Clinical Microbiology Research Center.

\section{References}

1. Kapoor A, Simmonds P, Scheel TK, Hjelle B, Cullen JM, Burbelo PD, et al. Identification of rodent homologs of hepatitis $C$ virus and pegiviruses. MBio. 2013;4(2):e00216-3.

2. Nakano T, Lau GM, Lau GM, Sugiyama M, Mizokami M. An updated analysis of hepatitis $C$ virus genotypes and subtypes based on the complete coding region. Liver Int. 2012;32(2):339-45.

3. Behzadi MA, Ziyaeyan M. Hepatitis C Virus Load in Seropositive Liver and Kidney Transplant Recipients by Quantitative RealTime PCR Before and After Transplantation.Jundishapur J Microbiol 2013;6(8)

4. Berenguer M. Natural history of recurrent hepatitis C. Liver Transpl. 2002;8(10 Suppl 1):S14-8.

5. Fishman JA, Rubin RH, Koziel MJ, Periera BJ. Hepatitis C virus and organ transplantation. Transplantation. 1996;62(2):147-54

6. Pereira BJ. Renal transplantation in patients positive for hepatitis B or C (con). Transplant Proc. 1998;30(5):2070-2.

7. Kamar N, Alric L, Izopet J, Rostaing L. Hepatitis C virus and kidney disease. Clin Res Hepatol Gastroenterol. 2013;37(4):328-33.

8. Morales JM, Aguado JM. Hepatitis C and renal transplantation. Curr Opin Organ Transplant. 2012;17(6):609-15.

9. Aoufi Rabih S, Garcia Agudo R. Management of HCV infection in chronic kidney disease. Nefrologia. 2011;31(3):260-7.

10. Latt N, Alachkar N, Gurakar A. Hepatitis C virus and its renal manifestations: a review and update. Gastroenterol Hepatol (NY). 2012;8(7):434-45.

11. Behzad-Behbahani A, Mojiri A, Tabei SZ, Farhadi-Andarabi A, Pouransari R, Yaghobi R, et al. Outcome of hepatitis B and C virus infection on graft function after renal transplantation. Transplant Proc. 2005;37(7):3045-7. 
12. Roche B, Samuel D. Hepatitis C virus treatment pre- and postliver transplantation. Liver Int. 2012;32 Suppl 1:120-8.

13. Chou R, Hartung D, Rahman B, Wasson N, Cottrell EB, Fu R. Comparative effectiveness of antiviral treatment for hepatitis $\mathrm{C}$ virus infection in adults: a systematic review. Ann Intern Med. 2013;158(2):114-23.

14. Zein NN. Clinical significance of hepatitis $C$ virus genotypes. Clin Microbiol Rev. 2000;13(2):223-35.

15. Keyvani H, Alizadeh AH, Alavian SM, Ranjbar M, Hatami S. Distribution frequency of hepatitis $\mathrm{C}$ virus genotypes in 2231 patients in Iran. Hepatol Res. 2007;37(2):101-3.

16. Samimi-Rad K, Nategh R, Malekzadeh R, Norder H, Magnius L. Molecular epidemiology of hepatitis $\mathrm{C}$ virus in Iran as reflected by phylogenetic analysis of the NS5B region. J Med Virol. 2004;74(2):246-52.

17. Zali MR, Mayumi M, Raoufi M, Nowroozi A. Hepatitis C virus genotypes in the Islamic Republic of Iran: a preliminary study. East Mediterr Health J. 2000;6(2-3):372-7.

18. Jahanbakhsh Sefidi F, Keyvani H, Monavari SH, Alavian SM, Fakhim S, Bokharaei-Salim F. Distribution of hepatitis $C$ virus genotypes in Iranian chronic infected patients. Hepat Month. 2013;13(1).

19. Ramia S, Eid-Fares J. Distribution of hepatitis $C$ virus genotypes in the Middle East. Int J Infect Dis. 2006;10(4):272-7.

20. Lok AS, Chien D, Choo QL, Chan TM, Chiu EK, Cheng IK, et al. Antibody response to core, envelope and nonstructural hepatitis $\mathrm{C}$ virus antigens: comparison of immunocompetent and immunosuppressed patients. Hepatology. 1993;18(3):497-502.

21. Thio CL, Nolt KR, Astemborski J, Vlahov D, Nelson KE, Thomas DL. Screening for hepatitis $C$ virus in human immunodeficiency virus-infected individuals. J Clin Microbiol. 2000;38(2):575-7.

22. Joukar F, Khalesi AK, Jafarshad R, Rahimabadi MS, MansourGhanaei F. Distribution of hepatitis C virus genotypes in haemodialysis patients of Guilan, northern Islamic Republic of Iran. East Mediterr Health J. 2012;18(3):236-40.

23. Chakravarti A, Dogra G, Verma V, Srivastava AP. Distribution pattern of HCV genotypes \& its association with viral load. Indian Med Res. 2011;133:326-31.

24. Payan C, Roudot-Thoraval F, Marcellin P, Bled N, Duverlie G, Fouchard-Hubert I, et al. Changing of hepatitis $C$ virus genotype patterns in France at the beginning of the third millenium: The GEMHEP GenoCII Study. JViral Hepat. 2005;12(4):405-13.

25. Ross RS, Viazov S, Renzing-Kohler K, Roggendorf M. Changes in the epidemiology of hepatitis C infection in Germany: shift in the predominance of hepatitis C subtypes. J Med Virol. 2000;60(2):122-5.

26. Seme K, Vrhovac M, Mocilnik T, Maticic M, Lesnicar G, Baklan Z, et al. Hepatitis C virus genotypes in 1,504 patients in Slovenia, 19932007. J Med Virol. 2009;81(4):634-9.

27. Alavian SM, Gholami B, Masarrat S. Hepatitis C risk factors in Iranian volunteer blood donors: a case-control study. J Gastroenterol Hepatol. 2002;17(10):1092-7.

28. Chlabicz S, Flisiak R, Lapinski TW, Kowalczuk O, WiercinskaDrapalo A, Pytel-Krolczuk B, et al. Epidemiological features of patients infected with HCV genotype 4 in Poland: Epidemiology of HCV genotype 4 in Poland. Hepat Month. 2011;11(3):191-4.

29. Savvas SP, Koskinas J, Sinani C, Hadziyannis A, Spanou F, Hadziyannis SJ. Changes in epidemiological patterns of HCV infection and their impact on liver disease over the last 20 years in Greece. JViral Hepat. 2005;12(5):551-7. 